This is the peer reviewed version of the following article:

Nagar B., J ovic M., Bassetto V.C., Zhu Y., Pick H. Gómez-Romero P., Merkoçi A., Girault H.H., Lesch A.. Highly Loaded Mildly Edge-Oxidized Graphene Nanosheet Dispersions for Large-Scale Inkjet Printing of Electrochemical Sensors. ChemElectroChem, (2020). 7. : 460 - . 10.1002/celc. 201901697 ,

which has been published in final form at https://dx.doi.org/10.1002/celc. 201901697. This article may be used for non-commercial purposes in accordance with Wiley Terms and Conditions for Use of Self-Archived Versions. 


\section{Highly loaded mildly edge-oxidized graphene nanosheet dispersions for large-scale inkjet printing of electrochemical sensors}

Bhawna Nagar, ${ }^{\mathrm{a}-\mathrm{c}}$ Milica Jović, ${ }^{\mathrm{c}}$ Victor Costa Bassetto, ${ }^{\mathrm{c}}$ Yingdi Zhu, ${ }^{\mathrm{c}}$ Horst Pick, ${ }^{\mathrm{d}}$ Pedro Gómez-

Romero, ${ }^{a}$ Arben Merkoçi, ${ }^{b}$ Hubert H. Girault ${ }^{c}$ and Andreas Lesche, ${ }^{*}$

[a] Dr. B. Nagar, Prof. P. Gómez-Romero Novel energy oriented Materials group

Catalan Institute of Nanoscience and Nanotechnology (ICN2), CSIC and The Barcelona Institute of Science and Technology

Campus UAB, Bellaterra, 08193 Barcelona, Spain

[b] Dr. B. Nagar, Prof. A. Merkoçi

Nanobioelectronics and Biosensors Group

Catalan Institute of Nanoscience and Nanotechnology (ICN2), CSIC and The Barcelona Institute of Science and Technology

Campus UAB, Bellaterra, Barcelona 08193, Spain; ICREA, Pg. Lluís Companys, 23, Barcelona 08010, Spain

[c] Dr. B. Nagar, Dr. V. Costa Bassetto, Dr. Y. Zhu, Prof. H. H. Girault

Laboratory of Physical and Analytical Electrochemistry (LEPA)

Ecole Polytechnique Fédérale de Lausanne (EPFL) Valais Wallis

Rue de l'Industrie 17, 1950 Sion, Switzerland

[d] Dr. H. Pick

Institute of Chemical Sciences and Engineering (ISIC)

Ecole Polytechnique Fédérale de Lausanne (EPFL)

EPFL Station 15, 1015 Lausanne, Switzerland

[e] Dr. A. Lesch

Department of Industrial Chemistry "Toso Montanari"

University of Bologna

Viale del Risorgimento 4, 40136 Bologna, Italy

E-mail: andreas.lesch@unibo.it 


\section{Abstract}

Inkjet printing of electrochemical sensors using a highly loaded mildly edge-oxidized graphene nanosheet (EOGN) ink is presented. An ink with $30 \mathrm{mg} / \mathrm{mL}$ EOGNs is formulated in a mixture of N-methyl pyrrolidone and propylene glycol with only $30 \mathrm{~min}$ of sonication. The absence of additives, such as polymeric stabilizers or surfactants, circumvents reduced electrochemical activity of coated particles and avoids harsh post-printing conditions for additive removal. A single light pulse from a xenon flash lamp dries the printed EGON film within a fraction of a second and creates a compact electrode surface. An accurate coverage with only $\sim 30.4 \mu \mathrm{g}$ of EOGNs per printed layer and $\mathrm{cm}^{2}$ is achieved. The EOGN films adhere well to flexible polyimide substrates in aqueous solution. Electrochemical measurements were performed using cyclic voltammetry and differential pulse voltammetry. An all inkjet-printed threeelectrode living bacterial cell detector is prepared with EOGN working and counter electrodes and silverbased quasi-reference electrode. The presence of $E$. coli in liquid samples is recorded with four electroactive metabolic activity indicators.

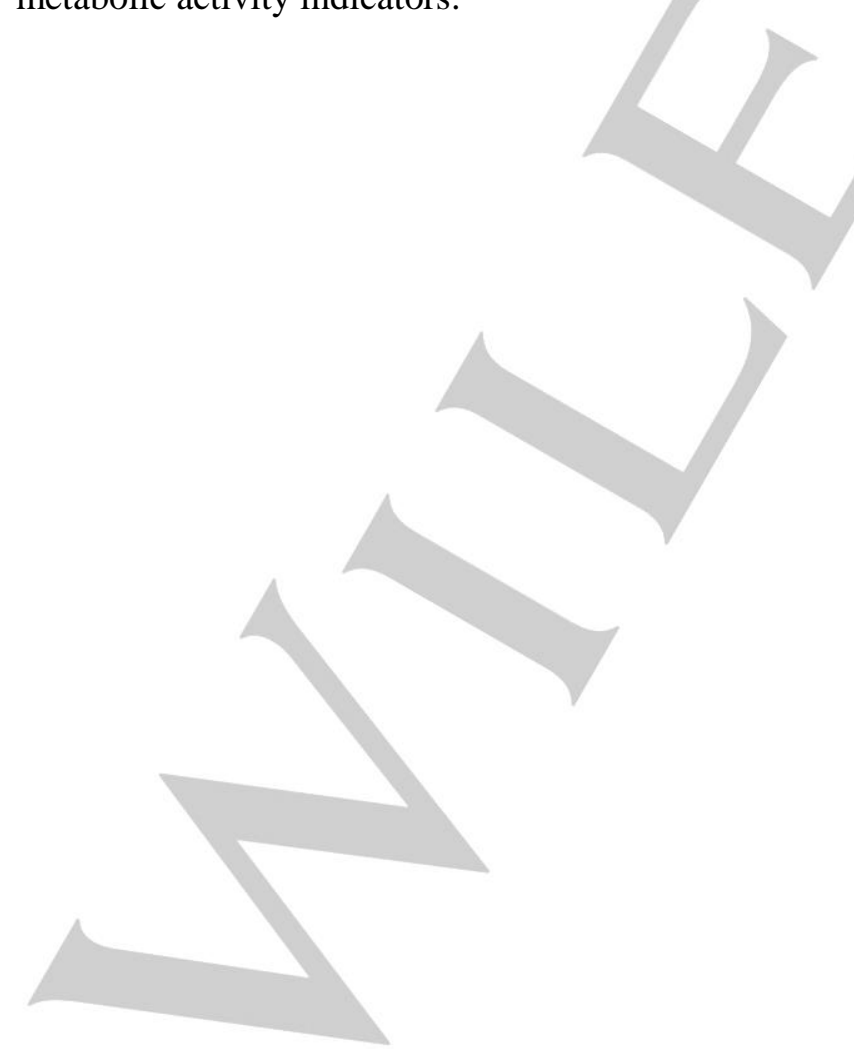




\section{Introduction}

Graphite is the state-of-the-art material for the sensing part of disposable and flexible electrochemical sensors. For decades, graphite-based sensors have pushed the development of screen-printing for largescale and low-cost sensor production, in particular contributing to the success story of the electrochemical glucose sensors. Screen printing of graphite-based carbon pastes through the meshes of masks is used for thick film patterns of several $\mu \mathrm{m}$ thickness, where high lateral micrometric resolution is not the primary requirement ${ }^{[1,2]}$. It is until now that screen printed graphite electrodes find a large range of applications due to the ability to detect a variety of compounds in environmental sensing and health care at low cost, including the modification of the graphite surface, such as with enzymes and catalytically active nanoparticles ${ }^{[3-5]}$. Sensors can be miniaturized and electronic components are compact, affordable and portable. Sensor production, including electrochemical sensors, is nowadays driven by digital and maskless, low-cost material deposition techniques, such as inkjet printing, as they provide a large range of flexible fabrication parameters compared to traditional, mask-based techniques. In terms of sensitivity and selectivity for many analytical purposes, other carbonaceous materials, such as carbon nanotubes (CNTs) and graphene, have shown their ability to improve sensing performance ${ }^{[6,7]}$. Such carbonaceous graphite alternatives can be costly, which can impede their use for large scale screen-printing, because a large amount of the material can be lost as ink residues on the mask. Therefore, material deposition techniques with low wastage, such as drop-on-demand inkjet printing, in which the ink is ejected from tiny nozzles on demand without the requirement of masks, got in the focus ${ }^{[8]}$.

Inkjet printing is further contactless and the generation of picoliter-sized droplets in combination with highly resolved positioners provides high accuracy also for multi-layer printing. Patterns are generated digitally providing the possibility of upscaling fabrication processes from prototype level to reach commercialization purposes, simply by increasing the number of activated nozzles in a printhead from a few to thousands. However, compared to screen-printing, the formulation of reproducible and stable inks creates often a bottleneck $[9,10]$. Nanoparticle aggregation and sedimentation in the printhead can block 
the nozzle orifice irreversibly. Furthermore, inks for piezoelectric-based printheads favor a surface tension and viscosity in the ranges of $28-33 \mathrm{mN} / \mathrm{m}$ and $10-12 \mathrm{cPs}$, respectively. For instance, piezoelectric actuation does not generate droplets with highly viscous inks while a high surface tension of the ink generates split droplets. Other requirements are related to the ink-substrate interaction, which influences the formation of homogeneous patterns, i.e., without particle sedimentation at the rims of the droplet due to a phenomenon known as coffee ring effect, and of films that are well adhered to the substrate. The latter is of high importance for sensors that will be in contact with a liquid and/or that operate also under bending ${ }^{[11-14]}$. Inkjet printing of a large range of materials has been reported ranging from metal/metal oxide nanoparticles ${ }^{[15-18]}$, polymers ${ }^{[19]}$ to carbonaceous materials like carbon black ${ }^{[20]}$, carbon nanotubes (CNTs) ${ }^{[21-24]}$ or graphene and its derivatives ${ }^{[25-27]}$. Metal nanoparticles, like $\mathrm{Ag}, \mathrm{Pt}, \mathrm{Au}$ or $\mathrm{Cu}$, are attractive for many sensing applications but are often expensive or unstable (e.g. due to chemical oxidation). On the contrary, CNTs or graphene are chemically and mechanically stable and possess exceptional thermal and electronic properties. ${ }^{[28,29]}$ Graphene can be produced on large scale by chemical oxidation or liquid-phase exfoliation of graphite ${ }^{[30,31]}$, but is generally difficult to disperse in liquids with the required properties (water mixed with organic solvents for low surface tension and elevated viscosity) due to strong inter-sheet attraction based on the $\pi$ - $\pi$-interactions between the aromatic $s p^{2}$ carbons from adjacent sheets ${ }^{[32,33]}$. As a rule of thumb for piezoelectric inkjet printing, the particle size (including agglomerates and aggregates) should be about one hundred times smaller than the dimension of the nozzle orifice, which means in the case of representative inkjet printers a particle size equal to $200 \mathrm{~nm}$. Generally, graphene derivatives are dispersed based on sonication and solvent selection ${ }^{[34]}$. The low solubility of pristine graphene leads often to the formulation of inks with extremely low loadings and, as a result, multiple printing passes are required in order to obtain a conductive film of interconnected sheets on a substrate. For instance, certain commercial graphene inkjet inks contain less than $0.1 \mathrm{wt} . \%(\sim 1 \mathrm{mg} / \mathrm{mL})$ of solids. However, replacing graphene by graphene oxide (GO), which is hydrophilic, can lead to high stability aqueous dispersions ${ }^{[34]}$. However, GO is less conductive (depending on the degree of oxidation of the graphene sheets) than pristine graphene 
and requires an additional step for its thermal, chemical or photonic reduction ${ }^{[35]}$. On the other hand, the aggregation of graphene sheets can be reduced or avoided by the addition of stabilizers, which include surfactants and polymers ${ }^{[36,37]}$. Using ink stabilizers, such as ethyl cellulose in cyclohexanone, terpineol and diethylene glycol methyl ether, prevent graphene sheet aggregation and increased the solid content of commercial inks to $\sim 3.4 \mathrm{mg} / \mathrm{mL}$. However, the use of stabilizers can result in low film conductivity or even insulating patterns, as the stabilizers electronically insulate the printed particles or create a large interparticle resistance. This requires high thermal post-processing steps $\left(>100^{\circ} \mathrm{C}\right)$ to remove the stabilizers and to sinter the particles together to form a conductive layer ${ }^{[38,39]}$. Another issue, decoupled from conductivity, is that stabilizers can cause electrode fouling (loss of sensitivity) and, when electroactive, show additional peaks in voltammograms (loss of selectivity and sensitivity). Aqueous inks are preferably used due to their absence or limited presence of toxicity. On the contrary, organic solvents, such as Nmethyl-pyrrolidone (NMP) can result in reasonably good graphene dispersions ${ }^{[34]}$ with the additional advantage of reducing the coffee ring effect in the stabiliser-free ink formulations ${ }^{[40]}$. As inkjet printers are automatized, they can be operated under personnel protecting conditions.

In this work, we present a simple, straightforward and up-scalable method for the formulation of an inkjet ink with exceptionally high loading of mildly edge-oxidized graphene nanosheets (EOGNs) based on short sonication and proper solvent combination. The ink primarily addressed the production of disposable electrochemical sensors and we present the ink formulation, printing parameters, such as number of printed layers, and rapid photonic annealing of the as-printed patterns. Accordingly, fully inkjet-printed threeelectrode electrochemical sensors containing EOGN working and counter electrodes and a silver-based quasi-reference electrode were characterized and employed for the detection of living bacterial cells $(E$. coli) in a liquid sample by following the metabolic reduction of the metabolic activity indicators (5-cyano2,3-di-(p-tolyl) tetrazolium chloride (CTC), 2-(4-iodophenyl)-3-(4-nitrophenyl)-5-(phenyl) tetrazolium chloride (INT), 2,3,5-triphenyl tetrazolium chloride (TTC) and resazurin (RS). The approach described herein addresses a rapid low-cost electrochemical bacteria YES/NO sensor. 


\section{Experimental Methods}

\subsection{Materials and Reagents}

Mildly edge-oxidized graphene nanosheets (EOGNs, 15-20 sheets, 4-10\% edge-oxidized, Sigma Aldrich), commercial silver ink (Silverjet DGP-40LT-15C, 30-35 wt.\%, Sigma Aldrich), UV curable dielectric ink (jettable insulator EMD 6201, Sun Chemical), N-methyl pyrrolidone (NMP), propylene glycol (PG), 2propanol, potassium hexacyanoferrate (III) $\left(\mathrm{K}_{3}\left[\mathrm{Fe}(\mathrm{CN})_{6}\right]\right)$, potassium hexacyanoferrate (II) $\left(\mathrm{K}_{4}\left[\mathrm{Fe}(\mathrm{CN})_{6}\right]\right)$, ferrocenemethanol $(\mathrm{FcMeOH})$, hexaamineruthenium (III) chloride $\left(\left[\mathrm{Ru}\left(\mathrm{NH}_{3}\right)_{6}\right] \mathrm{Cl}_{3}\right)$, potassium hexachloroiridate (III) $\left(\mathrm{K}_{3} \mathrm{IrCl}_{6}\right)$, potassium nitrate $\left(\mathrm{KNO}_{3}\right)$, lysogeny broth (Sigma-Aldrich), four metabolic activity indicators (5-cyano-2,3-di-(p-tolyl) tetrazolium chloride (CTC), 2-(4-iodophenyl)-3-(4nitrophenyl)-5-(phenyl) tetrazolium chloride (INT), 2,3,5-triphenyl tetrazolium chloride (TTC) and resazurin (RS); all Sigma-Aldrich), were of analytical grade and used as received. Aqueous solutions were prepared with ultrapure water (Millipore Milli-Q, specific resistivity $18.2 \mathrm{M} \Omega \cdot \mathrm{cm}$ ). Polyimide sheets (PI, Kapton HN, GoodFellow, thickness $125 \mu \mathrm{m}$ ) were used as substrates after rinsing with isopropyl alcohol and drying with a stream of nitrogen.

\subsection{Preparation of graphene ink}

The EOGN-based ink was prepared by adding $30 \mathrm{mg}$ of the EOGN powder to $1 \mathrm{~mL}$ of a mixture of NMP and PG in the volume ratio 7:3. The mixture was then sonicated for $30 \mathrm{~min}$ at $40 \%$ amplitude with an on/off pulse cycle of $5 \mathrm{~s}$ using a Sonics Vibra Cell 505 in the "cup horn" arrangement. The viscosity and surface tension of the ink were measured using a SV-10 A series viscometer (A\&D Instruments Limited) and a drop shape analyzer DSA-30 (Krüss). 


\subsection{Inkjet printing of EOGN patterns and three-electrode sensors}

EOGN patterns were inkjet printed on the PI sheets using a drop-on-demand DMP-2850 materials deposition printer (Fujifilm Dimatix) with disposable DMC-11610 cartridge. Jetting was realized by piezoelectric actuation of 16 individually addressable nozzles with $10 \mathrm{pL}$ nominal droplet volume. Printing parameters, including piezoelectric actuation, jetting frequency, the horizontal distance of the nozzle orifice to the substrate and substrate temperature were optimized. The substrate temperature was kept at $60{ }^{\circ} \mathrm{C}$ for fast evaporation of the ink solvents. After printing, the EOGN patterns were subjected to flash light sintering (also known as photonic curing) using a PulseForge 1300 (NovaCentrix) integrated into an X-Serie CeraPrinter (Ceradrop). The parameters of the high intensity pulsed light were $400 \mathrm{~V}$ for the lamp charging with a pulse width of $18 \mu$ s resulting in an energy density of $4.4 \mathrm{~J} / \mathrm{cm}^{2}$, measured with a BX-100 Bolometer (Novacentrix).

Three-electrode sensors comprised of a EOGN working electrode (WE), EOGN counter electrode (CE) and a silver quasi-reference electrode (QRE) were fully inkjet-printed using first the procedure above for the WE and CE. Printing of silver and a dielectric ink was adapted from our previous works ${ }^{[21] ~[41]}$. Briefly, the silver and dielectric inks were printed using the CeraPrinter with QS-256-80pL printhead comprised of 256 individually addressable nozzles and DMC-11610-10pL cartridge with 16 individually addressable nozzles, respectively. The UV curable dielectric ink was printed with simultaneous photo-polymerization by using a UV lamp (FireEdge FE300 380-420 nm, Phoseon Technology) integrated into the printhead carrier to define the areas of the electrodes and to insulate the conductive paths. $\mathrm{Ag}$ or $\mathrm{Ag} / \mathrm{AgCl}$ were used as QRE. For $\mathrm{Ag} / \mathrm{AgCl}$, silver electrodes were exposed for $3 \mathrm{~min}$ to a sodium hypochlorite solution ${ }^{[42][43]}$. All three electrodes (WE, QRE, CE) had an active area of $\sim 1 \mathrm{~mm}^{2}$.

\subsection{Materials characterization}

Inkjet-printed EOGN electrodes were analyzed by scanning electron microscopy (SEM, FEI Quanta 650 FEG ESEM) and high-resolution transmission electron microscopy (TEM, FEI Tecnai F20). X-ray 
photoelectron spectroscopy (XPS) was performed using a SPECS PHOIBOS 150 analyser (SPECS GmbH). Optical micrographs were taken with the built-in cameras of the CeraPrinter and DMP printer.

\subsection{Bacterial culture}

Escherichia coli (E. coli) strain DH5 $\alpha$ was grown as pre-culture in lysogeny broth at $37{ }^{\circ} \mathrm{C}$ for $6 \mathrm{~h}$ with continuous shaking at $200 \mathrm{rpm}$. $250 \mu \mathrm{L}$ of pre-culture was added into lysogeny broth and incubated for 2$3 \mathrm{~h}$ at $37^{\circ} \mathrm{C}$ with continuous shaking at $650 \mathrm{rpm}$. The obtained fresh cultures were afterwards used for measurements. Concentrations of bacterial cells in lysogeny broth were determined by measuring the optical density at $600 \mathrm{~nm}\left(\mathrm{OD}_{600 \mathrm{~nm}}\right)$ using $\mathrm{UV}$-visible absorbance spectroscopy $\left(1.0 \mathrm{OD}_{600 \mathrm{~nm}}\right.$ corresponds to $\sim 8 \times 10^{8}$ cells $\left./ \mathrm{mL}\right)$.

\subsection{Electrochemical measurements}

Electrochemical measurements, i.e., cyclic voltammetry (CV) and differential pulse voltammetry (DPV), were performed with a MultiEmStat (PalmSens) potentiostat in a three-electrode arrangement, using one EOGN pattern as the WE, the other EOGN pattern as $\mathrm{CE}$ and $\mathrm{Ag}$ or $\mathrm{Ag} / \mathrm{AgCl}$ as QRE. The system was operated using the PSTrace software. CV was applied for the electrochemical characterization of the printed sensors and redox indicators. DPV was applied as an exemplary pulsed voltammetric technique for bacteria detection following our previous works ${ }^{[44]}$. Experimental parameters for the CVs and DPVs are given in the according sections and figure captions (vide infra). In brief, the scan rate for CV was varied between 5 and $100 \mathrm{mV} / \mathrm{s}$. During DPVs, the potential was scanned from $0 \mathrm{~V}$ to $-0.8 \mathrm{~V}$ with a scan rate of $50 \mathrm{mV} / \mathrm{s}$ (potential pulse of $0.1 \mathrm{~V}$ with pulse time of $0.05 \mathrm{~s}$ and step potential $5 \mathrm{mV}$ ). The electrochemical characterization of the electrodes was performed in $2 \mathrm{mM} \mathrm{FcMeOH}$ or $2 \mathrm{mM} \mathrm{K} 3\left[\mathrm{Fe}(\mathrm{CN})_{6}\right] / \mathrm{K}_{4}\left[\mathrm{Fe}(\mathrm{CN})_{6}\right]$ with $0.1 \mathrm{M} \mathrm{KNO}_{3}$ as supporting electrolyte while bacteria detection measurements were performed in Lysogeny broth (LB) with a redox indicator concentration of $5 \mathrm{mM}$. All measurements were carried out under ambient conditions at room temperature using the electrochemical sensors as printed. 


\section{Results and Discussions}

\subsection{Ink formulation and inkjet printing}

The EOGN ink was formulated with the aim of fulfilling the following requirements: $(i)$ high dispersibility of the EOGN powder, (ii) stable jetting with piezoelectric driven printheads, (iii) fast drying of printed patterns and (iv) the possibility to fabricate homogeneous and conductive EOGN patterns with good adhesion to Kapton HN, in particular when the substrates with printed patterns are immersed in aqueous solutions for electrochemical measurements. NMP (viscosity $1.65 \mathrm{mPa} \cdot \mathrm{s}$ at $25^{\circ} \mathrm{C}$ ) was chosen as one ink component due to its known good properties for dispersing graphene ${ }^{[45][46]}$. In NMP, graphene concentrations of up to $63 \mathrm{mg} / \mathrm{mL}$ have been reported ${ }^{[47]}$. Propylene glycol (viscosity $40.4 \mathrm{mPa} \cdot \mathrm{s}$ at $25^{\circ} \mathrm{C}$ ) was used to increase both the viscosity of the ink for printing and the dispersibility of EOGNs over extended printing times (please see Supporting Information SI-1). Indeed, the presence of oxygenated groups requires a polar solvent and glycols have been reported to disperse well GO ${ }^{[48]}$. Mildly EOGNs (4-10\% edge oxidized) can be considered as graphene with few polar groups at the edges (SI-2). Recently, it was suggested that the sonication of graphene dispersions in mixed NMP and PG resulted in more effective exfoliation of graphene from graphite thanks to the higher viscosity induced by the presence of PG ${ }^{[49]}$. This is most likely due to a more efficient transfer of the shears during sonication in viscous liquids. The mixture of PG and NMP (3:7) allowed in this work to reach EOGN loadings of $30 \mathrm{mg} / \mathrm{mL}$ in inkjet printable inks, which to the best of our knowledge overcomes by far the loadings of current commercial and in literature reported inkjet printable graphene and graphene derivate-based inkjet inks. The solubility of graphene and its derivatives in literature is discussed considering solubility parameters and surface energies, but also by molecular dynamics simulations ${ }^{[34]}$. Following one of the currently discussed concepts, matching the surface free energy of graphene with the surface tension of the ink increases dispersion stability. Indeed, while graphene has a surface tension of $46.7 \mathrm{mN} / \mathrm{m}$ and graphene oxide $62.1 \mathrm{mN} / \mathrm{m}^{[50]}$, mildly EOGNs can be expected to be within this range. The NMP:EG ink had a surface tension $\gamma$ of $38 \mathrm{mN} / \mathrm{m}$ approaching this 
value indicating good dispersibility following this concept. While literature reported graphene concentrations are often based on UV/VIS spectra of the supernatant of long-term rested solutions, for inkjet printing of laboratory-made inks the initial loading of the fresh and printable ink is a major characteristic. Table 1 (full list in SI-3) shows a summary of different graphene inkjet ink formulations reported in literature. For instance, Karim et al. reported inkjet printing of a 2.4 wt.\% graphene ink made by mixing a commercial 8 wt.\% graphene dispersion (BS8) with 1\% PVP, a surfactant, triethylene glycol monomethyl ether and a 30-35 wt.\% Ag-nanoparticle ink for printing on textiles. ${ }^{[51]}$ Seekaew et al. printed a graphene-PEDOT:PSS composite ink as gas sensors for ammonia reaching up to $\sim 0.2 \mathrm{mg} / \mathrm{mL}$ graphene loading ${ }^{[52]}$. Electrochemically exfoliated graphene, which generated GO, was dispersed in a mixture of DMF, EG and glycerol reaching $~ 0.28$ wt. \% graphene ${ }^{[53]}$. High curing temperatures were required to reduce the GO back to conductive graphene. The graphene inks from Hersam and co-workers are the most known ones containing ethyl cellulose as stabilizer, and cyclohexanone and terpineol as solvents reaching 3.4 $\mathrm{mg} / \mathrm{mL}$ graphene inks ${ }^{[54]}$. The ink additives need to be thermally removed after printing.

Table 1: Exemplary graphene-based inkjet ink formulations reported in literature

\begin{tabular}{|c|c|c|c|c|c|c|}
\hline Material & $\begin{array}{c}\text { Graphene } \\
\text { loading / } \\
\text { mg/mL }\end{array}$ & $\begin{array}{c}\text { Stabilizers or } \\
\text { surfactants }\end{array}$ & Solvents & $\begin{array}{c}\text { Post- } \\
\text { printing } \\
\text { step }\end{array}$ & Substrate & Ref. \\
\hline $\begin{array}{c}\text { Graphene/ } \\
\text { Ag NP ink }\end{array}$ & $\sim 24$ & $\begin{array}{c}\text { Triton X-100 } \\
\text { and 1\% PVP }\end{array}$ & $\begin{array}{c}\text { Purchased } \\
\text { dispersions diluted in } \\
\text { Triethylene glycol } \\
\text { monomethyl ether }\end{array}$ & $\begin{array}{c}150{ }^{\circ} \mathrm{C} \text { for } \\
1 \mathrm{~h}\end{array}$ & $\begin{array}{c}\text { Paper and } \\
\text { textiles }\end{array}$ & [51] \\
\hline $\begin{array}{c}\text { Graphene/ } \\
\text { PEDOT:PSS } \\
\text { aqueous } \\
\text { solution) }\end{array}$ & $\sim 0.2$ & Triton X-100 & Water/DMSO/EG & N/A & $\begin{array}{c}\text { Transparent } \\
\text { flexible } \\
\text { plastic } \\
\text { substrate }\end{array}$ & [52] \\
\hline $\begin{array}{c}\text { electrochemi } \\
\text { cally } \\
\text { exfoliated } \\
\text { graphene }\end{array}$ & 2.8 & $\begin{array}{c}\text { None graphene } \\
\text { contained } \\
\text { defects) }\end{array}$ & $\begin{array}{c}\text { DMF:EG:Glycerol } \\
50: 45: 5\end{array}$ & $\begin{array}{c}300 \text { and } \\
500{ }^{\circ} \mathrm{C}\end{array}$ & $\begin{array}{c}\text { "plastic", } \\
\text { glass }\end{array}$ & [53] \\
\hline
\end{tabular}




\begin{tabular}{|c|c|c|c|c|c|c|}
\hline Graphene & 3.4 & $\begin{array}{c}\text { EC 5\% in } \\
\text { toluene/ethano } \\
180: 20\end{array}$ & $\begin{array}{c}85 \% \text { cyclohexane } \\
15 \% \text { terpineol }\end{array}$ & $\begin{array}{c}\text { HMDS } \\
250{ }^{\circ} \mathrm{C} \text { for } \\
30 \mathrm{~min} \\
\text { modified } \\
\mathrm{Si} / \mathrm{SiO}_{2} \\
\text { wafers and } \\
\text { PI }\end{array}$ & [54] \\
\hline $\begin{array}{c}\text { Mildly } \\
\text { EOGNs }\end{array}$ & 30 & None & $\begin{array}{c}\text { NMP : PG } \\
7: 3\end{array}$ & $\begin{array}{c}\text { Photonic } \\
\text { Curing }\end{array}$ & PI & $\begin{array}{c}\text { This } \\
\text { Work }\end{array}$ \\
\hline
\end{tabular}

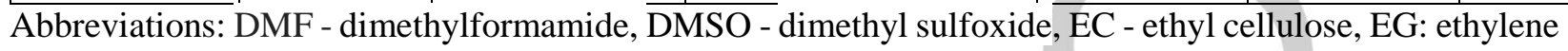
glycol, EOGN - edge-oxidzed graphene nanosheet, HMDS - hexamethyldisilazane, NMP - N-methyl pyrrolidone, PEDOT:PSS - poly(3,4-ethylenedioxythiophene) poly(styrenesulfonate), PVP Polyvinylpyrrolidone.

The physical and rheological properties of the ink were adjusted to allow piezoelectric-based inkjet printing.

The ink exhibited a density $\rho$ of $1.05 \mathrm{~g} / \mathrm{cm}^{3}$, dynamic viscosity $\eta$ of $3.8 \mathrm{mPa} \cdot \mathrm{s}$ and surface tension $\gamma$ of 38 $\mathrm{mN} / \mathrm{m}$. A dimensionless $Z$ parameter, which is the inverse of the Ohnesorge number $(\mathrm{Oh})$ and derived from the Reynolds (Re) and Weber (We) numbers, was calculated with Equation 1 to estimate if the formulated EOGN ink is within the printability range of $1<Z<10$, as defined by Derby ${ }^{[55]}$ :

$$
Z=\frac{1}{\mathrm{Oh}}=\frac{\sqrt{\gamma \rho a}}{\eta}
$$

where $a$ is a characteristic length. A $Z$-value $>10^{[55]}$ can result in satellite droplets formation, while inks with a $Z$ value $<1$ are often too viscous resulting in difficulties for droplet ejection ${ }^{[10,56]}$. The $Z$ number for the EOGN ink was 7.5 (using the nozzle orifice diameter of $21.5 \mu \mathrm{m}$ as $a$ ) and stable jetting of $11.3 \mathrm{pL}$ droplets was observed with all 16 nozzles available in the printhead (Fig. 1a, droplet ejection in SI-4). The piezoelectric actuation, which is based on a voltage pulse with defined duration, slew rate and firing voltage was adjusted starting from a default pulse provided by the printer manufacturer. Good wetting by the EOGN ink on the PI substrate was demonstrated by a contact angle of $15.2^{\circ}{ }^{[57]}$ indicating that overlapping droplets might result in homogeneous films (Fig. 1b). Arrays of individual droplets were printed and the high regularity of the droplet positions and diameters of $\sim 60 \mu \mathrm{m}$ demonstrates the stability of jetting (Fig. 1c). Thereafter, rectangular patterns of EOGNs (geometrical area $5 \mathrm{~mm}^{2}$ ) with up to 20 inkjet-printed layers (IJPLs) were fabricated. Fig. 1d shows an example of two rectangles printed with 20 IJPLs. Please note 
that one IJPL refers to the deposition of one droplet per coordinate and not to a single EOGN layer. Adjacent droplets were interpenetrated by $25 \mu \mathrm{m}$ resulting in a droplet-to-droplet distance of $35 \mu \mathrm{m}$. Larger distances can create holes in the patterns while an access of ink can run over the pattern edges causing a loss of pattern resolution. The darkness of the patterns gradually increased with the number of IJPLs due to the increasing amount of deposited EOGNs. Even after 20 printing passes, the patterns were well defined demonstrating the high resolution of the printing process. Based on the known droplet volume, the droplet density on the substrate and the graphene loading, it was possible to calculate the accurately printed EOGN loading of $\sim 30.4 \mu \mathrm{g}_{\mathrm{EOGN}} /\left(\mathrm{IJPL} \cdot \mathrm{cm}^{2}\right)$. After the printing process, the EOGN wet films were subjected to photonic flash sintering. The EOGNs absorbed the emitted light stronger than the PI substrate and generated sufficient heat to dry and to adhere the EOGN film to PI ${ }^{[58]}$. The conductivity of the patterns was examined by using a voltmeter and varied from $\sim 140 \mathrm{k} \Omega / \mathrm{mm}$ for 2 IJPLs to $\sim 0.4 \mathrm{k} \Omega / \mathrm{mm}$ for 20 IJPLs. This indicates an increase in film conductivity with IJPL, as expected. For electrochemical sensing applications, voltammograms were recorded to get figures of merit of the film conductivity (vide infra). 


\section{ARTICLE}
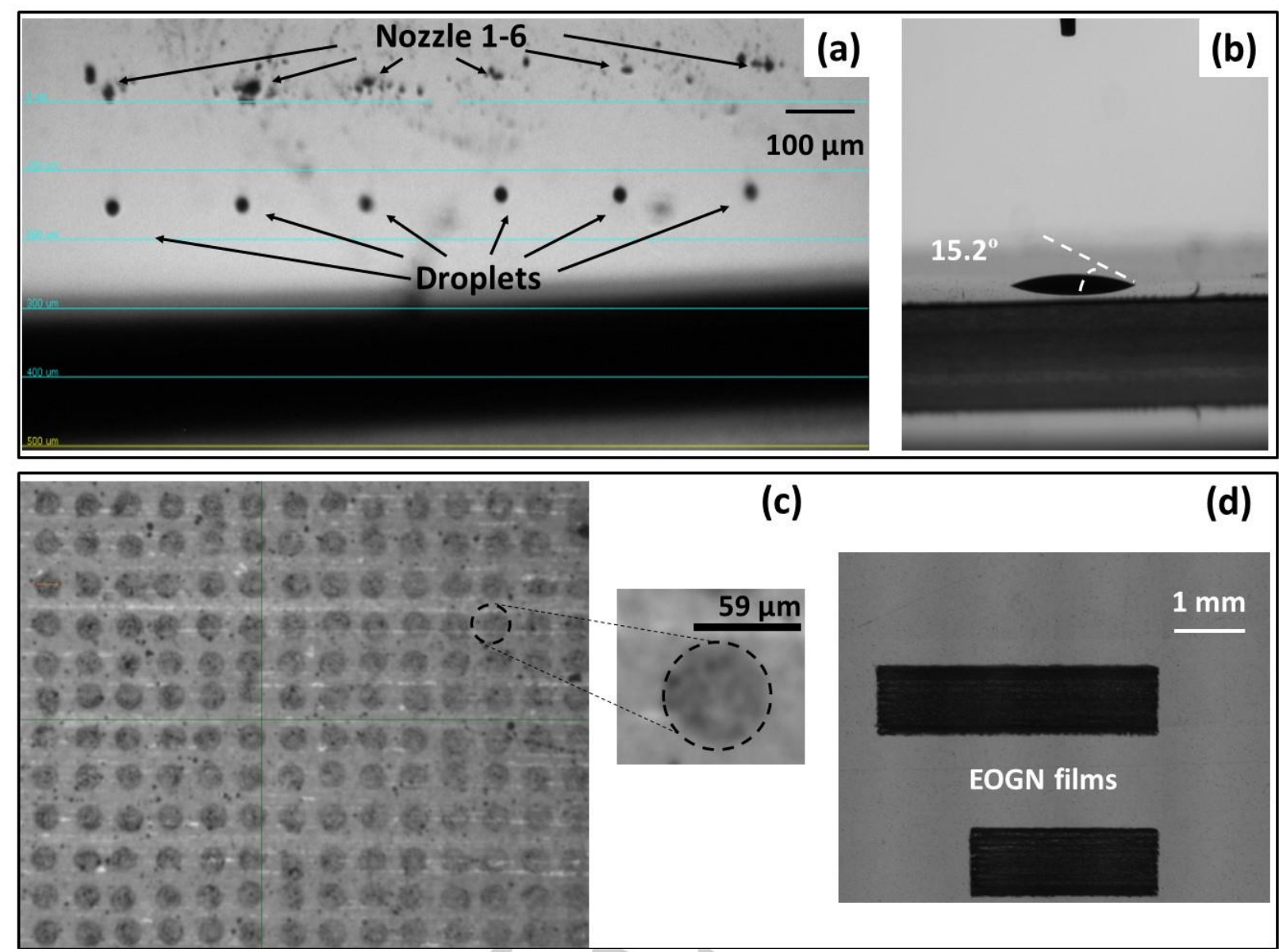

(c)

(d)
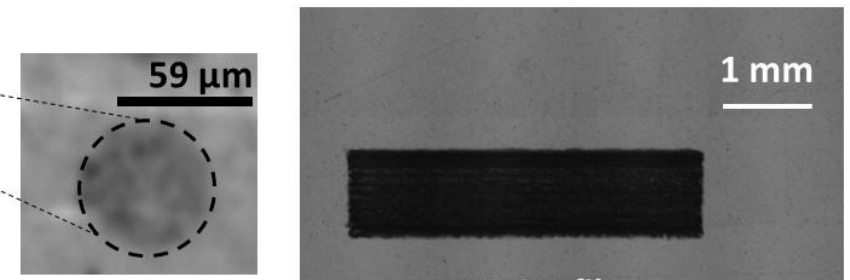

EOGN films

Figure 1. (a) Representative jetting of EOGN ink from six consecutive nozzles. (b) Contact angle measurement of EOGN ink on Kapton HN. (c) Dried droplet array of EOGN ink on PI substrate with a lateral droplet separation of $100 \mu \mathrm{m}$. (d) Two EOGN patterns with 20 IJPLs on PI.

A three-electrode sensor composed of two EOGN patterns as WE and CE and a silver quasi-reference electrode (QRE) was fabricated in three steps (Fig. 2a): (i) inkjet printing and photonic flash sintering of EOGNs, (ii) inkjet printing and photonic flash sintering of silver as conducting paths and QRE, and (iii) inkjet printing with simultaneous UV photo-polymerization of UV-curable dielectric ink to form the electrical insulation layer and to precisely define all three active electrode areas. Fig. $2 \mathbf{b}$ shows a microscopic image of the final sensor design taken with the printer camera, while photographs of nine individual sensors are shown in Fig. 2c. 


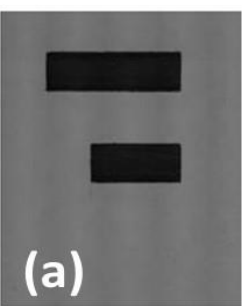

Step 1:

Printing of EOGN Film

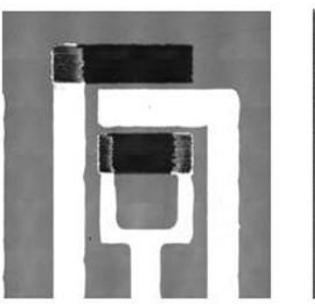

Step 2:

Printing of $\mathrm{Ag}$ connections

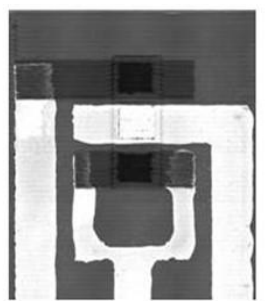

Step 3:

Printing of Insulation
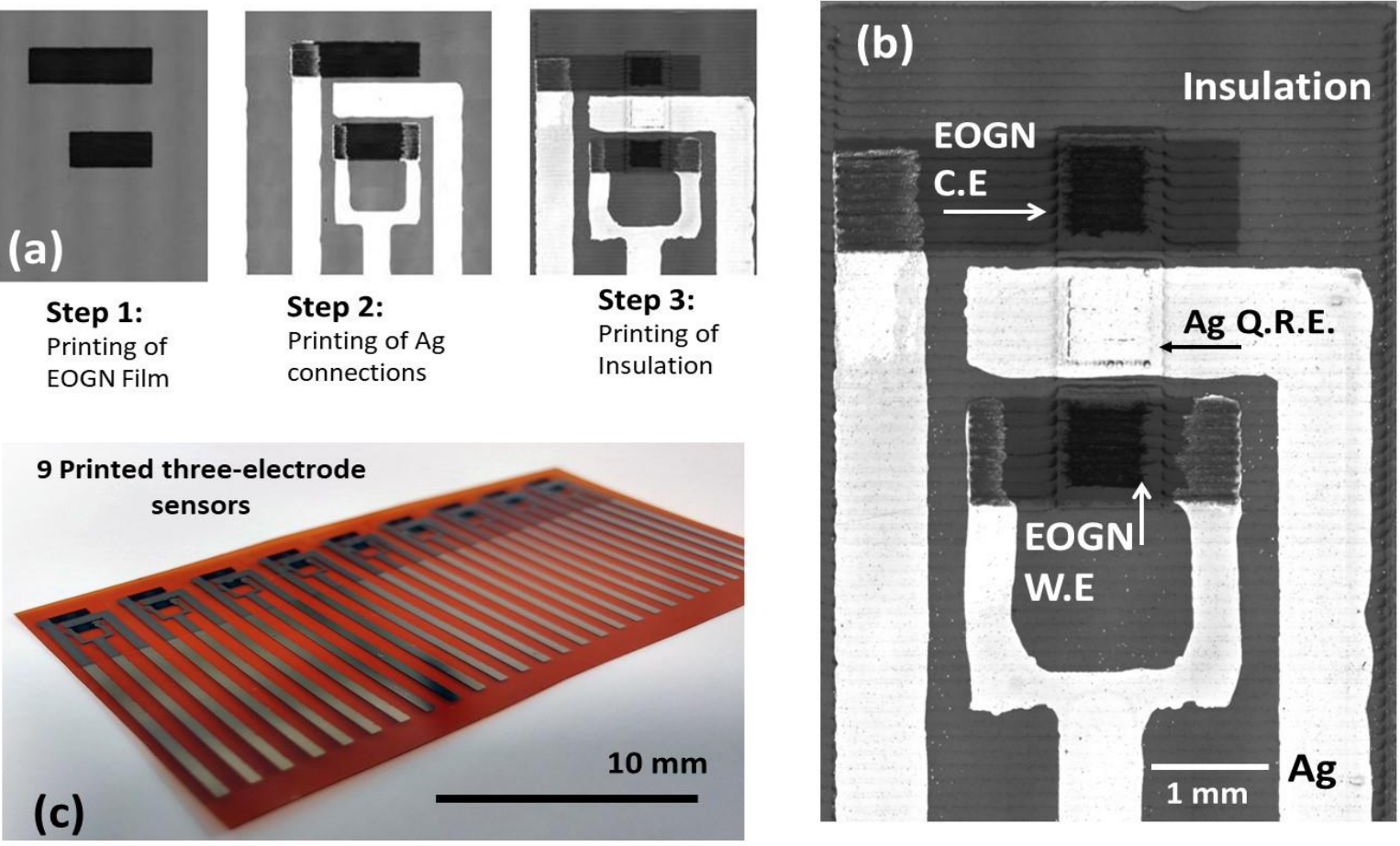

Figure 2. (a) Schematic image of the fabrication process of three-electrode sensors. (b) Image of final sensor design taken with the printer camera. (c) Photograph of multiple fabricated sensors.

\subsection{Morphological Characterization}

An SEM image of the raw EOGN powder shows flakes of $\sim 4 \mu \mathrm{m}$ in length (Fig. 3a), while the TEM image of EOGNs taken from the inkjet ink, i.e. after the sonication in the NMP and propene glycol mixture, shows sheets with lateral dimensions in the nanometer range (Fig. 3b). Different layers (2-20) of stacked graphene sheets were observed in correspondence with SAED data (selected area electron diffraction, Fig. 3d inset). It exhibits hexagonal rings with a six-fold symmetric pattern, attributing to graphene, with different and multiple spot sizes. This can be credited to the multilayer graphene stackings, presence of domain boundaries and /or intrinsic rotational ${ }^{[59]}$. The first hexagon of reflections refers to an inter-plane distance of $2.13 \AA$ and the outer hexagon refers to $1.23 \AA$ corresponding to the $\{0110\}$ to $\{1210\}$ planes ${ }^{[60,61]}$. Notably, the size of the EOGN flakes in a pattern obtained from the ink was considerably reduced to 200 $400 \mathrm{~nm}$ (Fig. 3d) compared to the raw EOGN powder (Fig. 3a). 
Fig. 3e shows the XPS spectra of the printed EOGN pattern before (i.e. after removing the patterns from the printer hot plate, $60^{\circ} \mathrm{C}$ ) and after photonic curing using a $400 \mathrm{~V}$ pulse a width of $18 \mu$ s generating a theoretical total shot energy of $6.9 \mathrm{~J} / \mathrm{cm}^{2}$. In the core level C1s spectra of both printed patterns, the peaks corresponding to $\mathrm{C}=\mathrm{C}$ graphitic carbon at $284.4 \mathrm{eV}, \mathrm{C}-\mathrm{C} s p^{3}$ at 285.5 and $\mathrm{C}=\mathrm{O}$ carbonyl groups at 288.7 can be seen. Also, a peak at $291.3 \mathrm{eV}$ appears that can be attributed to the $\pi$ - $\pi^{*}$ shape-up satellite peak or the tail corresponding to $\mathrm{C}=\mathrm{C}$ graphitic peaks after the photonic curing ${ }^{[62,63]}$. XPS data shows the reduction of the atomic oxygen content from $9.0 \%$ to $6.2 \%$, indicating a reduction of the EOGNs induced by the light from the Xe flash lamp. Such reductive, light induced curing has recently been described by Secor et al. ${ }^{[64]}$, and Costa Bassetto et al. ${ }^{[65]}$ where certain compounds, such as alcohols can act as the reducing agents, while the temperature in the irradiated materials can reach several hundred degrees ${ }^{[66]}$. Indeed, several works on flash lamp-based curing/reducing of graphene oxide films as a cost- and time-efficient process have been reported ${ }^{[16,67,68]}$.

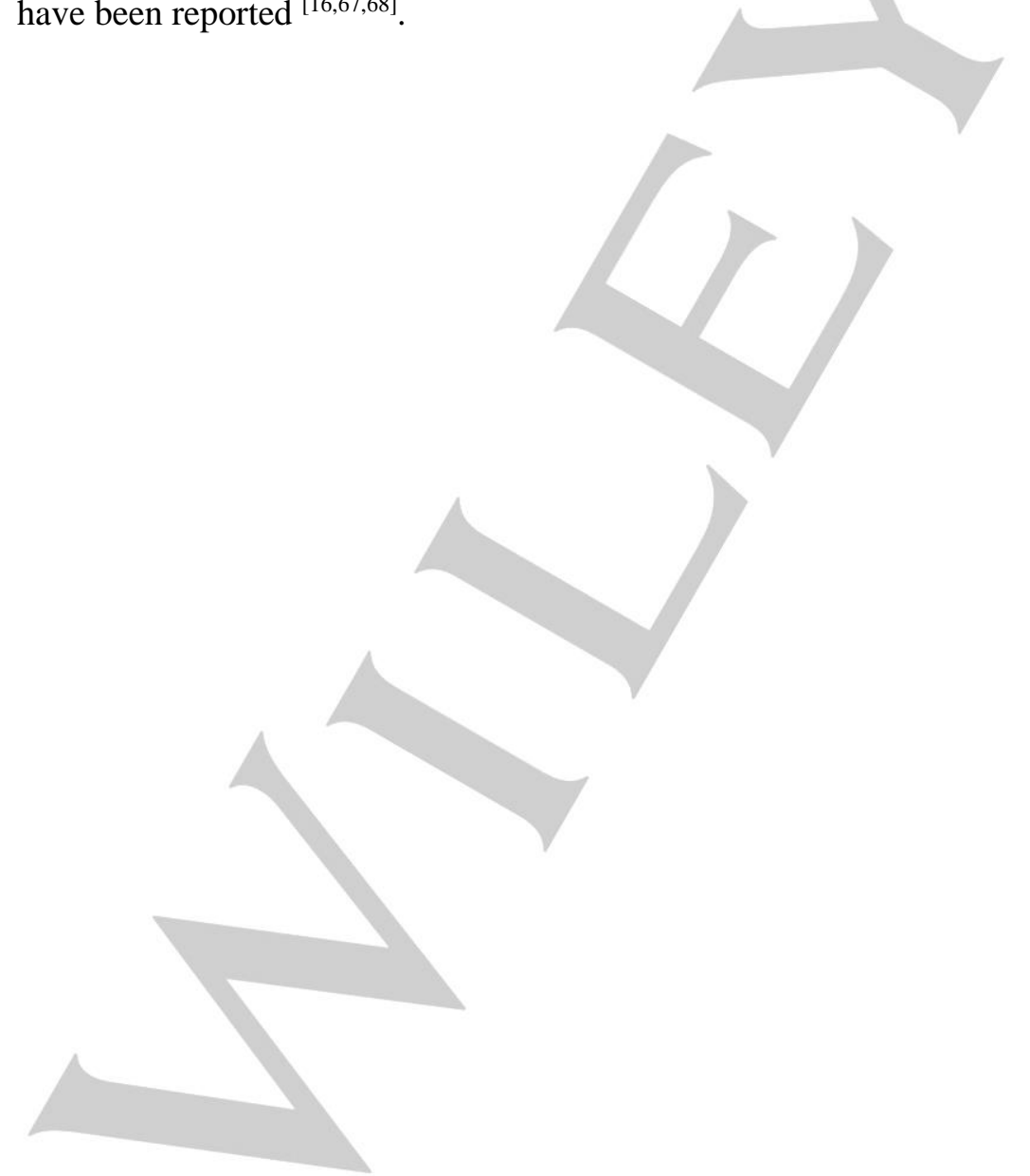




\section{ARTICLE}
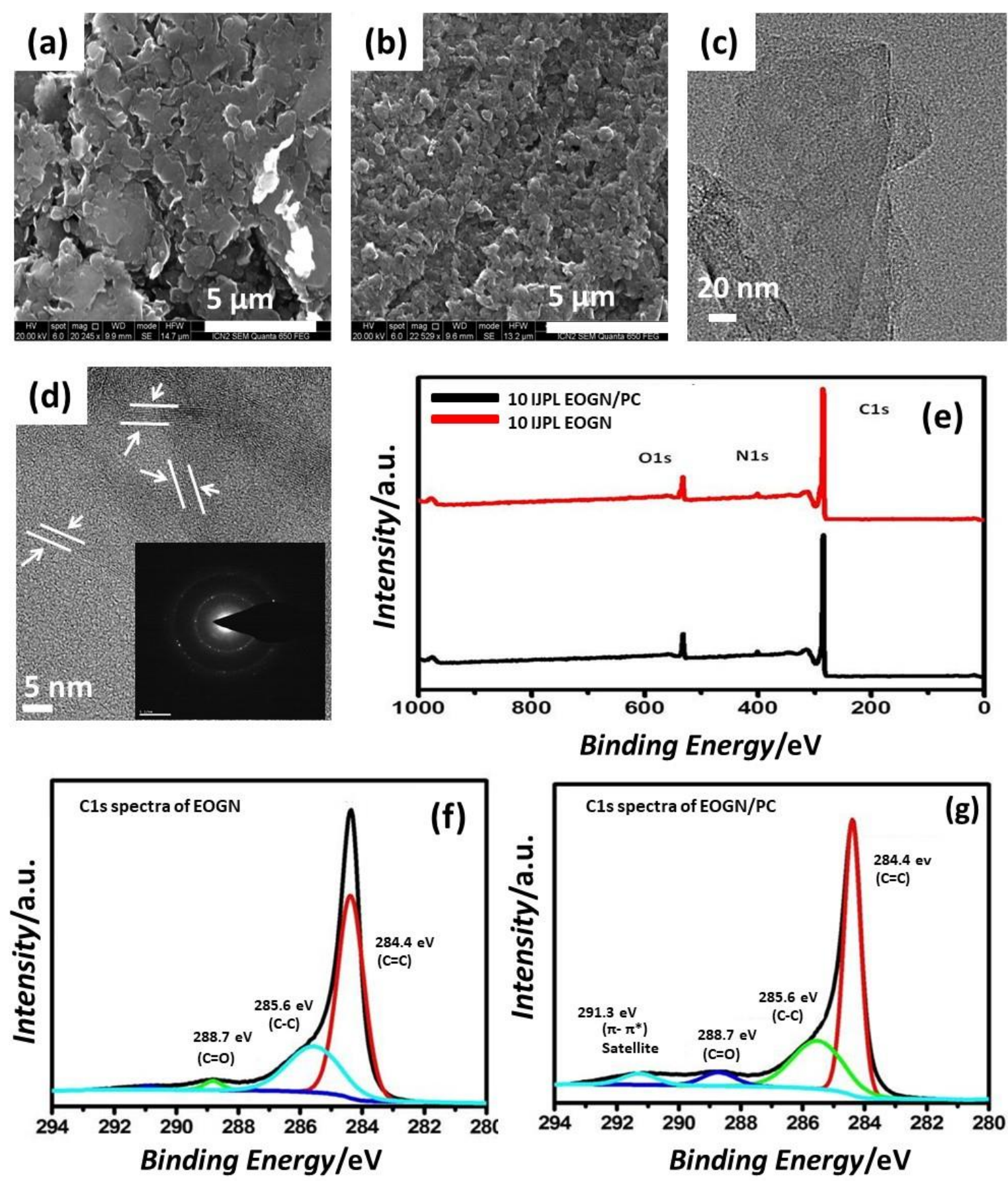

Figure 3. (a) SEM image of raw EOGN powder. (b) SEM image of inkjet-printed and flash sintered EOGN pattern with 10 IJPLs. (c) and (d) TEM images of EOGNs taken from the EOGN ink with inset of Selected area electron diffraction (SAED) pattern. (e) Full XPS spectra of inkjet-printed EOGN patterns before (black) and after (red) photonic curing. (f) Core level C1s XPS spectrum of EOGN before photonic curing and (g) Core level C1s of XPS spectrum of EOGN after photonic curing. 


\subsection{Electrochemical characterization}

The electrochemical characterization of EOGN working electrodes was performed by cyclic voltammetry (CV) using FcMeOH as electroactive species (Fig. 4a). FcMeOH has been shown in our previous works as an ideal electroactive compound for the characterization of carbon-based electrode materials ${ }^{[69,70]}$. As seen in Fig. 4a, an oxidation peak is seen at $0.248 \mathrm{mV}$ and a reduction peak at $0.171 \mathrm{mV}$ for $10 \mathrm{IJPLs}$ at 50 $\mathrm{mV} / \mathrm{s}$. However, both the peak currents and capacitive currents increased with increasing IJPL, indicating an increase of the real surface area of the WE as well as of the porosity of the entire electrode, respectively. Notably, electrochemical signals could be observed even with only 2 IJPLs, implying good graphene coverage with percolated nanosheets forming an electrode. Peak currents increased linearly with IJPL, but above 10 IJPLs a plateau (inset in Fig. 4a) was approached due to the fact that each additional EOGN printed layer did not increase further the real active electrode surface, possibly through blocking of porous parts at the bottom of the EGON film. The peak-to-peak-separation was closest to $59 \mathrm{mV}$ with $10 \mathrm{IJPLs}$ (76 $\pm 2 \mathrm{mV}$ at $50 \mathrm{mV} / \mathrm{s}, 3$ sensors). Based on these observations, 10 IJPLs were selected as the optimum number of IJPLs for the EOGN WE in further studies. However, since FcMeOH evidently showed a reduced reduction peak in the reverse half scans (diagnostic CV analysis in SI-5) the electroactive species was changed and a $2 \mathrm{mM}$ solution of a 1:1 mixture of $\left[\mathrm{Fe}(\mathrm{CN})_{6}\right]^{4-}$ and $\left[\mathrm{Fe}(\mathrm{CN})_{6}\right]^{3-}$ in $0.1 \mathrm{M} \mathrm{KNO}_{3}$ was used for all following experiments. The electrochemical response of the as-printed EOGN patterns heated just at $100{ }^{\circ} \mathrm{C}$ for $1 \mathrm{~h}$ under $\mathrm{N}_{2}$ was stable and printed patterns were conductive with good adhesion to PI when exposed to aqueous solutions. The electrochemical reduction and oxidation of $\left[\mathrm{Fe}(\mathrm{CN})_{6}\right]^{3-}$ and $\left[\mathrm{Fe}(\mathrm{CN})_{6}\right]^{4-}$ can be seen at $\sim 0.13 \mathrm{~V}$ and $\sim 0.04 \mathrm{~V}$, respectively (Fig. 4b). However, a significant contribution of capacitive currents was observed on the recorded CVs, most likely due to the porosity of the printed EOGN film. In order to reduce the capacitive contribution, which is favoured for analytical sensing applications, the electrochemical response after two different post-treatment steps was compared: 1) thermal curing (TC) at $300{ }^{\circ} \mathrm{C}$ for $1 \mathrm{~h}$ under $\mathrm{N}_{2}$ in a furnace, and 2) non-equilibrium photonic flash sintering using the $400 \mathrm{~V}$ pulse for one short light flash. With increasing curing temperature to $300{ }^{\circ} \mathrm{C}$ or by flash sintering the 
contribution of the capacitive current decreased and the redox peaks were more pronounced (Fig. $4 \mathbf{b})$. This could be attributed to the formation of a more compact EOGN film with reduced porosity. The reduction of capacitive signals could further suggest that the edge functionalities/defects on the graphene sites were reduced with partial restoration of the $s p^{2}$ structure. It has been shown that the capacitance of graphene is higher at the edges than the basal planes as the edges provide greater accessibility to the solvent ions and large inhomogeneities of the charges allow greater ion adsorption ${ }^{[71-73]}$. It must be noted that the temperature of the EOGN film during the photonic curing process is unknown due to the lack of temperature sensors that operate on microsecond time scales. The thermal treatment in a furnace is limited by the thermal properties of the plastic substrates. Herein, we used PI, which is resistant until nearly $400{ }^{\circ} \mathrm{C}$ (glass transition temperature $\vartheta_{\mathrm{g}}$ between 360 - $410^{\circ} \mathrm{C}$ ), but other plastics, such as polyethylene terephthalate (PET) cannot resist such temperatures $\left(\vartheta_{\mathrm{g}}\right.$ between $\left.67-81{ }^{\circ} \mathrm{C}\right)$. The peak-to-peak separation of the three $\mathrm{CVs}$ shown in Fig. 4a were $110 \pm 10 \mathrm{mV}$ for $\mathrm{TC}$ at $100{ }^{\circ} \mathrm{C}, 100 \pm 20 \mathrm{mV}$ for $\mathrm{TC}$ at $300{ }^{\circ} \mathrm{C}$ and only $87 \pm 9 \mathrm{mV}$ for photonic flash sintering. The lowest value herein for the photonic cured sample confirms the improved electrode performance.

A scan rate dependence study (more details and graphs in SI-6) showed a linear dependence of the anodic peak current $I_{\mathrm{pa}} v s$. the square root of the scan rate $\left(v^{1 / 2}\right)$, indicating a process controlled by semi-infinite linear diffusion as envisaged (Fig. 4c). Together with the peak-to-peak separation $\left(\Delta E_{\mathrm{p}}=83.4 \pm 4.0 \mathrm{mV}\right.$ $\mathrm{mV}$ ) and the ratio of the anodic and cathodic peak currents it can be assumed that the electrode reaction is quasi-reversible. The $\Delta E_{\mathrm{p}}$ value larger than $59 \mathrm{mV}$ could be due to the kinetics but also due to an $I R$-drop. Such IR-drop could be created by the resistance in the EOGN film. For insulated traces, this contribution was minimized by using highly conductive Ag (vide supra). Additionally, defects present in the graphenebased electrode could play a role for the enlarged peak separation ${ }^{[74,75]}$. These observations were confirmed with other electroactive species that were $\left[\mathrm{IrCl}_{6}\right]^{3-}$ and $\left[\mathrm{Ru}\left(\mathrm{NH}_{3}\right)_{6}\right]^{3-}(\mathbf{S I}-\mathbf{7}$ and SI-8).

Finally, the repeatability of the electrode fabrication process was studied by analysing 25 three-electrode sensors (with Ag QRE and EOGN as CE) (Fig. 4d). Almost identical electrode responses (i.e., curve shapes 
ARTICLE

and peak heights) were obtained for the 25 tested sensors (10 IJPLs for WE and CE) with an RSD for the anodic peak currents $I_{\mathrm{pa}}$ of $3.3 \%$, and a peak-to-peak separation of $(73 \pm 6) \mathrm{mV}$ at $50 \mathrm{mV} / \mathrm{s}$ demonstrating high reproducibility of the sensor fabrication process.
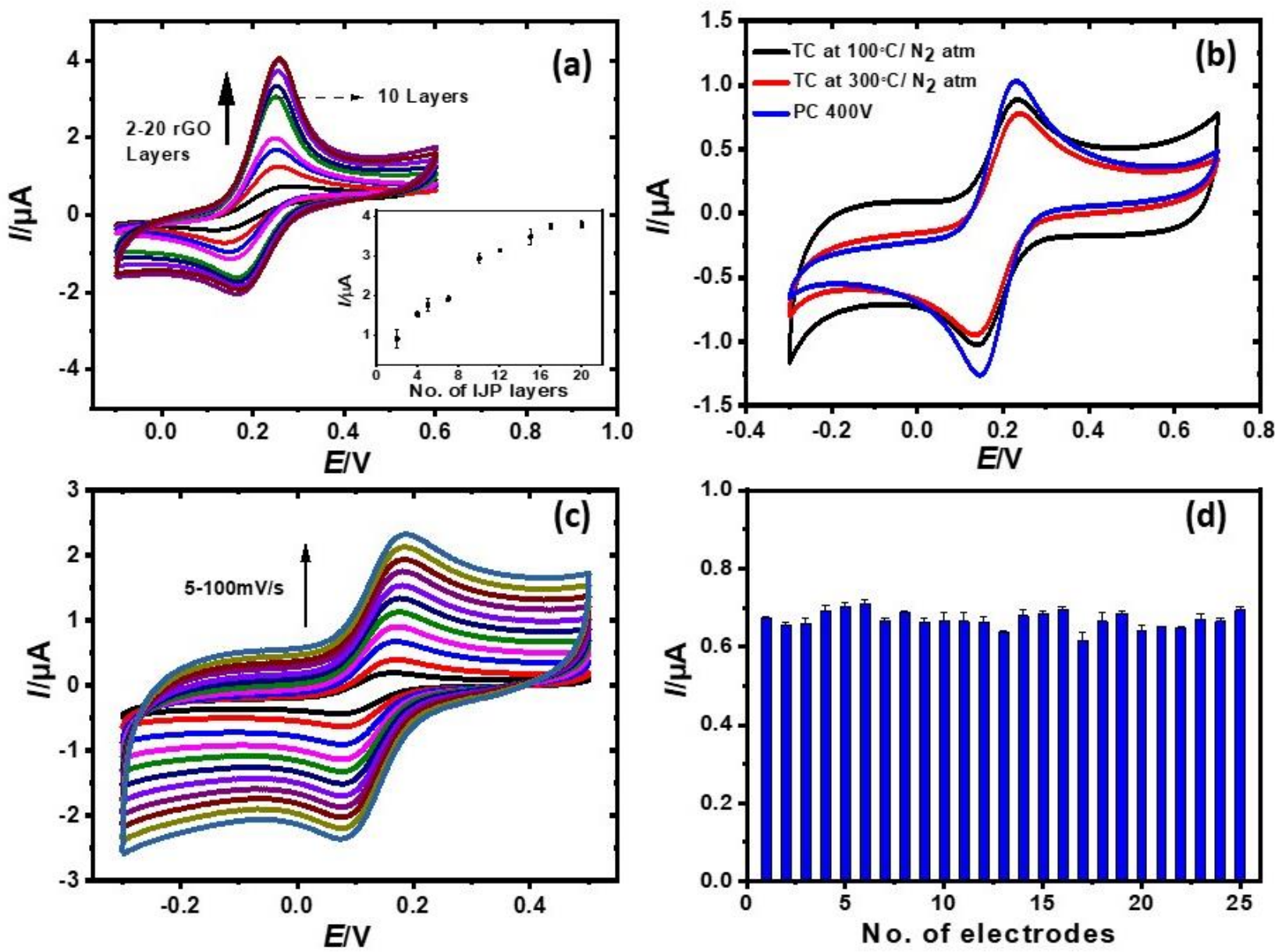

Figure 4. (a) Influence of the number of IJPLs on the CVs obtained in the presence of $2 \mathrm{mM} \mathrm{FcMeOH}$ and $0.1 \mathrm{M}$ $\mathrm{KNO}_{3}$ at $50 \mathrm{mV} / \mathrm{s}$. (b) Effect of thermal (TC) and photonic curing (PC) on the CVs of the EOGN electrode. (c) Effect of the scan rate $(5-100 \mathrm{mV} / \mathrm{s})$. (d) Repeatability study of 25 sensors. Error bars indicate the standard deviation ( $\mathrm{N}$ =3). (b), (c) and (d) in $2 \mathrm{mM} \mathrm{K}_{3}\left[\mathrm{Fe}(\mathrm{CN})_{6}\right] / \mathrm{K}_{4}\left[\mathrm{Fe}(\mathrm{CN})_{6}\right]$ and $0.1 \mathrm{M} \mathrm{KNO}_{3}$ with a scan rate of $50 \mathrm{mV} / \mathrm{s}, 10 \mathrm{IJPLs}$.

\subsection{Living bacterial cell detection}

Bacterial detection techniques usually employ antibodies (labelled or un-labelled), enzymes, DNAs or even a whole cell (micro-organism) as the bioreceptors ${ }^{[76]}$, but also redox mediator-assisted electrochemical 
sensing has been reported ${ }^{[76]}$. The classical procedure of living bacterial cell detection with redox indicators is based on the metabolic consumption (cellular reduction) of the redox indicator (i.e., a compound that can be reduced by the uptake of an electron) by the respiratory electron transport chain of living bacterial cells [77,78]. The consumption of the redox indicator is time-dependent and can be used for the detection and quantification of living bacterial cells in a liquid sample ${ }^{[44]}$. This concept has been known and is welladopted in colorimetric bacteria assays, but recently also found application in electrochemical sensing as many of the known metabolic activity indicators are electro-active ${ }^{[44]}$. Voltammetric reduction signals for the oxidized redox indicator decay in the presence of living bacterial cells. In our previous work, bacteria were captured by antibody-coated magnetic beads and concentrated on a specialized carbon nanotube electrode with a magnet below and a well plate on top to keep the reaction solution near the electrode ${ }^{[44]}$. The use of antibodies facilitates the detection of bacteria from species level, but the immune-affinity capture process is labor-intensive and time consuming. In this work, the EOGN-based sensor system was used as a simple YES/NO detector for living bacterial cells. The EOGN and ink materials employed were cheaper and easier to prepare than the CNT-based sensors used previously. Indeed, for many purposes, for instance to identify the presence of bacteria and their antibiotic resistance, quantification is less of concern, as long as the number of bacteria is above the limit of detection. In a first measurement, the presence of living bacteria is confirmed (YES answer), in a following second experiment with added antibiotics the presence of living bacterial cells (YES answer) indicates antimicrobial resistance while a NO answer indicates that the bacteria are susceptible. The inkjet-printed EOGN-based sensors can be loaded with a drop of only 5 $\mu \mathrm{L}$ achieving full electrodes coverage.

The electrochemical performances of four metabolic redox indicators typically employed in commercial colorimetric bacteria viability kits (RS, CTC, TTC and INT, structures and redox reactions in SI-9) was examined on EOGN electrodes by using both CV and DPV (Fig. 5). Lysogeny broth (LB) was used as a cell medium/supporting electrolyte solution. Electrochemical measurements were performed in the potential window from 0 to $-0.8 \mathrm{~V}$ and the indicator concentration was in all cases $5 \mathrm{mM}$. Cyclic 
voltammetry was carried out by scanning towards negative potentials in order to electrochemically reduce the redox dyes, demonstrating irreversibility for TTC, CTC and INT characterized by the missing oxidation peaks in the reverse scans. By reduction, tetrazolium salts are converted into their formazans (SI-9). The tetrazolium salts showed reduction peaks of different shapes and at different potentials depending on their molecular structure. Resazurin showed two reduction peaks $(-0.2 \mathrm{~V}$ and $-0.36 \mathrm{~V})$, from which the first corresponded to the irreversible reduction of RS to resorufin and the second to the reversible reduction to dihydroresorufin (SI-9) ${ }^{[44]}$. Afterwards, the electrochemical response of the redox indicator solutions without bacteria and with bacteria $\left(\sim 8.3 \times 10^{8} \mathrm{E}\right.$. coli cells $/ \mathrm{mL}$ with $30 \mathrm{~min}$ incubation) were investigated. In the presence of bacteria $\left(0.5 \mathrm{~mL}\right.$ of $\sim 8.3 \times 10^{8} \mathrm{E}$. coli cells $)$, the decrease of the reduction peaks for all redox indicators was evident, confirming that the EOGN electrodes could be successfully employed for the detection of living bacterial cells. Differential pulse voltammetry (DPV) was performed to get an indication about the sensitivity, which was highest for CTC due to a relative decrease of the DPV peak of about $94 \%$. On the contrary, RS, TTC and INT showed only relative DPV signal decays of $60 \%, 19 \%$ and $35 \%$, respectively. The measurements herein were performed in LB with bacterial cells of one species. Real matrices might cause interferences and require further sample preparation, such as centrifugation, supernatant disposal, washing and redispersing in LB. Specificity can be achieved by capturing and washing of the captured bacteria using immunoassay-based approaches ${ }^{[44]}$. In addition, electrochemical detection in complex matrices might require a protecting layer on the EOGN working electrode, for instance by a polyacrylamide-based nano-hydrogel layer as recently demonstrated for long term measurements of bacterial metabolites in artificial wound fluids ${ }^{[23]}$. The YES/NO response about the presence of living bacterial cells based on the relative DPV peak decay is used in a non-quantitative way, which can even allow the use of electrodes made with less reproducibility than the ones presented herein. Main factors for the selection of a redox indicator for the electrochemical detection of living bacterial cells are the electroactivity of the redox indicator with unequivocal peaks in the DPVs, the chemical stability of the redox indicator during the time of the analysis and the fast metabolic reduction of the redox indicator by the living 
bacterial cells. In the present case, CTC appeared to be the most suitable compound as it showed the largest decay of the DPV peak at the EOGN electrode under the applied experimental conditions.
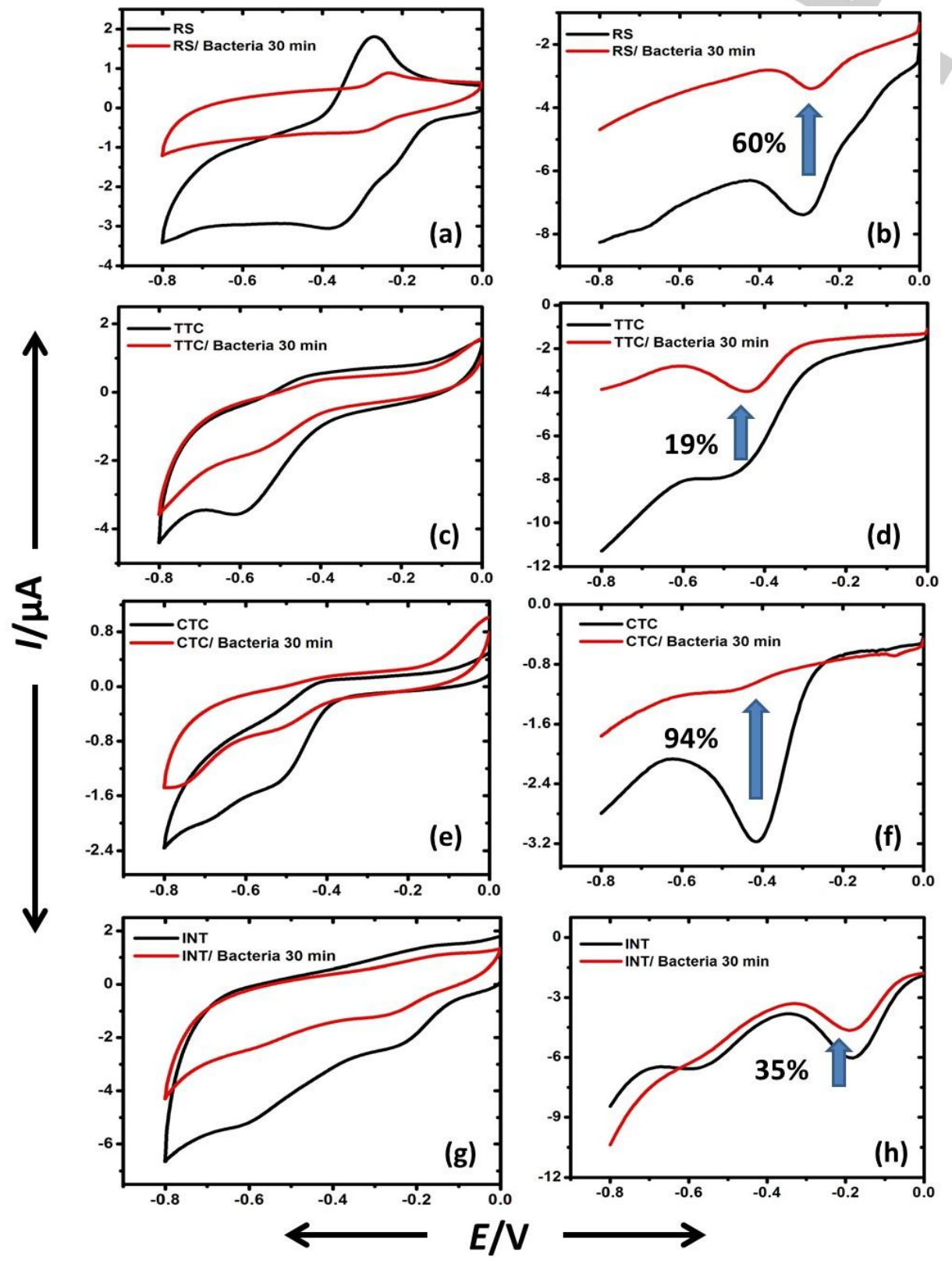

Figure 5. Electrochemical living bacterial cell detector based on inkjet-printed EOGN electrodes (10 IJPLs of EOGNs). CVs (left panels) and DPVs (right panels) for the following electroactive metabolic markers: RS (Resazurin) (a, b), TTC (2,3,5-triphenyl tetrazolium chloride) (c, d), CTC (5-cyano-2,3-di-(p-tolyl) tetrazolium chloride) (e, f) and INT (2-(4-iodophenyl)-3-(4-nitrophenyl)-5-(phenyl) tetrazolium chloride) $(\mathrm{g}, \mathrm{h}$ ). Blanks (LB without bacteria) are shown in black. Measurements in solutions with bacteria (initially $0.5 \mathrm{~mL}$ of $8.3 \times 10^{8} \mathrm{E}$. coli cells $/ \mathrm{mL}$, strain DH5alpha) after $30 \mathrm{~min}$ of incubation are shown in red. CV parameters: scan rate $50 \mathrm{mV} / \mathrm{s}$; DPV parameters: scan 
rate $50 \mathrm{mV} / \mathrm{s}$, step potential $5 \mathrm{mV}$, potential pulse $100 \mathrm{mV}$ and pulse time $0.05 \mathrm{~s}$. In (b), (d), (f) and (h) the relative decays of the DPV peaks are shown.

\section{Conclusions}

Simple and straightforward, yet highly effective, inkjet printing of graphene-based electrodes on flexible substrates was achieved thanks to the successful formulation of a highly loaded $30 \mathrm{mg} / \mathrm{mL}$ ink containing mildly edge-oxidized graphene nanosheets. The ink was surfactant- and stabilizer-free allowing after short drying with a light pulse from a flash lamp the direct use as electrochemical sensors in which the EOGN films showed remarkable adhesion to polyimide substrates. The EOGN electrodes exhibited quasireversible behavior with peak-to-peak separations below $80 \mathrm{mV}$ for several relevant electro-active species. Three-electrode sensors were used as viable bacteria detectors by the detection of redox indicators whose initial concentration in liquid samples is reduced solely when living bacterial cells are present.

Although various graphene inkjet inks are reported in literature and are nowadays also commercially available, we believe that our ink overcomes most of them for the use in electrochemical sensors. The ink can be patterned and used for a variety of flexible electrical or electrochemical applications. Combined inkjet printing and flash sintering of EOGNs is rapid, facile and reliable at low cost, potentially reaching $<20$ cents per sensor (material costs), offering mass production opportunities of flexible sensors for pointof-care applications.

\section{Acknowledgements}

B. N., P. G. R. and A. M. acknowledge the support from the Spanish MINECO under projects MAT201452485-P, PCIN-2016- 66 (program Euronanomed) and from the Secretaria d'Universitats i Recerca del Departament d'Economia i Coneixement de la Generalitat de Catalunya (Grant 1 SGR 260).

This work was also funded by the CERCA Programme/Generalitat de Catalunya. ICN2 was supported by the Severo Ochoa program from Spanish MINECO (Grant No. SEV-2013-0295).

B. N. acknowledges the Autonomous University of Barcelona (UAB) for the possibility of performing this work inside the framework of the Material Science (Department of Chemistry) PhD Programme. 
A. L. acknowledges the support from the Italian Ministry of Education, Universities and Research (Ministero dell'Istruzione, dell'Università e della Ricerca - MIUR) through a "Rita Levi Montalcini" grant (N. PGR16DTCYB).

\section{Keywords}

bacteria detection; graphene; inkjet printing; redox indicators; sensors

\section{References}

[1] S. Centi, A. I. Stoica, S. Laschi, M. Mascini, Electroanalysis 2010, 22, 1881-1888.

[2] B. Nagar, M. Balsells, A. de la Escosura-Muñiz, P. Gomez-Romero, A. Merkoçi, Biosens. Bioelectron. 2019, 129, 238-244.

[3] M. Hosseini Ghalehno, M. Mirzaei, M. Torkzadeh-Mahani, Bioelectrochemistry 2019, 130, 107322.

[4] H. Beitollahi, S. G. Ivari, M. Torkzadeh-Mahani, Biosens. Bioelectron. 2018, 110, 97-102.

[5] D. Voccia, F. Bettazzi, E. Fratini, D. Berti, I. Palchetti, Anal. Bioanal. Chem. 2016, 408, 72717281.

[6] H. M. Mohamed, TrAC Trends Anal. Chem. 2016, 82, 1-11.

[7] S. Cinti, F. Arduini, Biosens. Bioelectron. 2017, 89, 107-122.

[8] N. Komuro, S. Takaki, K. Suzuki, D. Citterio, Anal. Bioanal. Chem. 2013, 405, 5785-5805.

[9] H. Yoo, C. Kim, Colloids Surfaces A Physicochem. Eng. Asp. 2015, 468, 234-245.

[10] B. Derby, Annu. Rev. Mater. Res. 2010, 40, 395-414.

[11] P. He, J. R. Brent, H. Ding, J. Yang, D. J. Lewis, P. O’Brien, B. Derby, Nanoscale 2018, 10, 5599-5606.

[12] Y. Aleeva, B. Pignataro, J. Mater. Chem. C 2014, 2, 6436-6453.

[13] S. Lawes, A. Riese, Q. Sun, N. Cheng, X. Sun, Carbon N. Y. 2015, 92, 150-176.

[14] G. Hu, J. Kang, L. W. T. Ng, X. Zhu, R. C. T. Howe, C. G. Jones, M. C. Hersam, T. Hasan, Chem. Soc. Rev. 2018, 47, 3265-3300.

[15] M. Jović, J. C. Hidalgo-Acosta, A. Lesch, V. C. Bassetto, E. Smirnov, F. Cortés-Salazar, H. H. Girault, J. Electroanal. Chem. 2018, 819, 384-390.

[16] E. B. Secor, T. Z. Gao, M. H. Dos Santos, S. G. Wallace, K. W. Putz, M. C. Hersam, ACS Appl. Mater. Interfaces 2017, 9, 29418-29423.

[17] I. Reinhold, in Nanomater. 2D 3D Print., John Wiley \& Sons, Ltd, 2017, pp. 27-49.

[18] A. Kamyshny, S. Magdassi, Small 2014, 10, 3515-3535.

[19] B.-J. de Gans, P. C. Duineveld, U. S. Schubert, Adv. Mater. 2004, 16, 203-213.

[20] S. Cinti, N. Colozza, I. Cacciotti, D. Moscone, M. Polomoshnov, E. Sowade, R. Baumann, F. Arduini, Sensors Actuators B Chem. 2018, 265, DOI 10.1016/j.snb.2018.03.006.

[21] A. Lesch, F. Cortés-Salazar, M. Prudent, J. Delobel, S. Rastgar, N. Lion, J. D. Tissot, P. Tacchini, H. H. Girault, J. Electroanal. Chem. 2014, 717-718, 61-68.

[22] R. P. Tortorich, J.-W. Choi, Nanomaterials 2013, 3, 453-468.

[23] R. Jarošová, S. E. Mcclure, M. Gajda, M. Jović, H. H. Girault, A. Lesch, M. Maiden, C. Waters, G. M. Swain, Anal. Chem. 2019, 91, 8835-8844.

[24] D. M. Stanković, M. Jović, M. Ognjanović, A. Lesch, M. Fabián, H. H. Girault, B. Antić, 
Microchim. Acta 2019, 186, 532.

[25] L. Dybowska-Sarapuk, K. Kielbasinski, A. Arazna, K. Futera, A. Skalski, D. Janczak, M. Sloma, M. Jakubowska, Nanomaterials 2018, 8, 602.

[26] T. Homola, J. Pospíšil, R. Krumpolec, P. Souček, P. Dzik, M. Weiter, M. Černák, ChemSusChem 2018, 11, 941-947.

[27] T. Juntunen, H. Jussila, M. Ruoho, S. Liu, G. Hu, T. Albrow-Owen, L. W. T. Ng, R. C. T. Howe, T. Hasan, Z. Sun, et al., Adv. Funct. Mater. 2018, 28, 1-8.

[28] Novoselov K. S., Geim A. K, Nat. Mater. 2007, 6, 1-14.

[29] A. K. Geim, Science (80-. ). 2014, 1530, 1530-1534.

[30] C. N. R. Rao, U. Maitra, H. S. S. R. Matte, Graphene Synth. Prop. Phenom. 2012, 1-47.

[31] S. Gambhir, R. Jalili, D. L. Of, G. G. Wallace, 2015, DOI 10.1038/am.2015.47.

[32] S. Kholghi, A. Chinnappan, W. A. D. M. Jayathilaka, M. Khatibzadeh, E. Kowsari, S. Ramakrishna, Appl. Mater. Today 2017, 9, 372-386.

[33] A. V Eletskii, I. M. Iskandarova, A. A. Knizhnik, J. S. Ponraj, Z. Xu, S. Chander, n.d.

[34] D. W. Johnson, B. P. Dobson, K. S. Coleman, Curr. Opin. Colloid Interface Sci. 2015, 20, 367382.

[35] R. K. Singh, R. Kumar, D. P. Singh, RSC Adv. 2016, 6, 64993-65011.

[36] P. Li, C.-A. Tao, B. Wang, J. Huang, T. Li, J. Wang, J. Nanosci. Nanotechnol. 2018, 18, 713-718.

[37] Y. Gao, W. Shi, W. Wang, Y. Leng, Y. Zhao, Ind. Eng. Chem. Res. 2014, 53, 16777-16784.

[38] G. Hu, J. Kang, L. W. T. Ng, X. Zhu, R. C. T. Howe, C. G. Jones, M. C. Hersam, T. Hasan, Chem. Soc. Rev. 2018, 47, 3265-3300.

[39] W. Yang, C. Wang, J. Mater. Chem. C 2016, 4, 7193-7207.

[40] M. V. Bracamonte, G. I. Lacconi, S. E. Urreta, L. E. F. Foa Torres, J. Phys. Chem. C 2014, 118, $15455-15459$.

[41] M. Jović, Y. Zhu, A. Lesch, A. Bondarenko, F. Cortés-Salazar, F. Gumy, H. H. Girault, J. Electroanal. Chem. 2017, 786, 69-76.

[42] E. Silva, S. Miserere, L. Kubota, A. Merkoçi, Anal. Chem. 2014, 86, DOI 10.1021/ac503029q.

[43] M. Jović, F. Cortés-Salazar, A. Lesch, V. Amstutz, H. Bi, H. H. Girault, J. Electroanal. Chem. 2015, 756, 171-178.

[44] Y. Zhu, M. Jović, A. Lesch, L. Tissières Lovey, M. Prudent, H. Pick, H. H. Girault, Angew. Chemie Int. Ed. 2018, 57, 14942-14946.

[45] Y. Hernandez, M. Lotya, D. Rickard, S. D. Bergin, J. N. Coleman, 2010, 3, 3208-3213.

[46] F. Torrisi, T. Hasan, W. Wu, Z. Sun, A. Lombardo, T. S. Kulmala, G. W. Hsieh, S. Jung, F. Bonaccorso, P. J. Paul, et al., ACS Nano 2012, 6, 2992-3006.

[47] U. Khan, H. Porwal, A. O’Neill, K. Nawaz, P. May, J. N. Coleman, Langmuir 2011, 27, $9077-$ 9082.

[48] D. Konios, M. M. Stylianakis, E. Stratakis, E. Kymakis, J. Colloid Interface Sci. 2014, 430, 108112.

[49] M. A. Diasio, D. L. Green, MRS Adv. 2019, 4, 241-247.

[50] S. Wang, Y. Zhang, N. Abidi, L. Cabrales, Langmuir 2009, 25, 11078-11081.

[51] N. Karim, S. Afroj, K. S Novoselov, S. G Yeates, Sci. Rep. 2019, 8035 (2019, 1-10.

[52] Y. Seekaew, S. Lokavee, D. Phokharatkul, A. Wisitsoraat, T. Kerdcharoen, C. Wongchoosuk, Org. Electron. physics, Mater. Appl. 2014, 15, 2971-2981.

[53] F. Miao, S. Majee, M. Song, J. Zhao, S. L. Zhang, Z. Bin Zhang, Synth. Met. 2016, 220, 318-322.

[54] E. B. Secor, P. L. Prabhumirashi, K. Puntambekar, M. L. Geier, M. C. Hersam, J. Phys. Chem. Lett. 2013, 4, 1347-1351.

[55] B. Derby, J. Eur. Ceram. Soc. 2011, 31, 2543-2550.

[56] P. He, B. Derby, 2D Mater. 2017, 4, aa629e.

[57] D. S. Saidina, N. Eawwiboonthanakit, M. Mariatti, S. Fontana, C. Hérold, J. Electron. Mater. 2019, 48, 3428-3450. 
[58] C. Bauer, J.-P. Abid, H. H. Girault, Chem. Phys. 2005, 319, 409-421.

[59] A. W. Robertson, J. H. Warner, Nano Lett. 2011, 11, 1182-1189.

[60] J. C. Meyer, A. K. Geim, M. I. Katsnelson, K. S. Novoselov, T. J. Booth, S. Roth, Nature 2007, 446,60 .

[61] K. Ji, J. Han, A. Hirata, T. Fujita, Y. Shen, S. Ning, P. Liu, H. Kashani, Y. Tian, Y. Ito, et al., Nat. Commun. 2019, 10, 275.

[62] W. Gao, L. B. Alemany, L. Ci, P. M. Ajayan, Nat. Chem. 2009, 1, 403-408.

[63] C. K. Chua, M. Pumera, J. Mater. Chem. 2012, 22, 23227-23231.

[64] E. B. Secor, B. Y. Ahn, T. Z. Gao, J. A. Lewis, M. C. Hersam, Adv. Mater. 2015, 27, 6683-6688.

[65] V. Costa Bassetto, J. Xiao, E. Oveisi, V. Amstutz, B. Liu, H. H. Girault, A. Lesch, Appl. Catal. A Gen. 2018, 563, 9-17.

[66] S. Das, G. Gu, P. C. Joshi, B. Yang, T. Aytug, C. M. Rouleau, D. B. Geohegan, K. Xiao, J. Mater. Chem. A 2016, 4, 9685-9690.

[67] S. J. Choi, S. J. Kim, I. D. Kim, NPG Asia Mater. 2016, 8, 1-10.

[68] C. L. J, C.-S. R, H. J, J. Am. Chem. Soc. 2009, 131, 11027-11032.

[69] A. Lesch, F. Cortés-Salazar, V. Amstutz, P. Tacchini, H. H. Girault, Anal. Chem. 2015, 87, 10261033.

[70] A. Lesch, D. Momotenko, F. Cortés-Salazar, F. Roelfs, H. Girault, G. Wittstock, Electrochim. Acta 2013, 110, 30-41.

[71] C. Zhan, Y. Zhang, P. T. Cummings, D. en Jiang, Carbon N. Y. 2017, 116, 278-285.

[72] D. A. C. Brownson, L. J. Munro, D. K. Kampouris, C. E. Banks, RSC Adv. 2011, 1, 978-988.

[73] A. J. Pak, E. Paek, G. S. Hwang, J. Phys. Chem. C 2014, 118, 21770-21777.

[74] J. Electroanal, U. Parts, P. Cedex, 1983, 147, 39-51.

[75] D. a. C. Brownson, C. E. Banks, The Handbook of Graphene Electrochemistry - Chapter 2 Interpreting Electrochemistry, 2014.

[76] S. Kuss, H. M. A. Amin, R. G. Compton, Chem. - An Asian J. 2018, 13, 2758-2769.

[77] J. O’Brien, I. Wilson, T. Orton, F. Pognan, Eur. J. Biochem. 2000, 267, 5421-5426.

[78] K. Ishiki, D. Q. Nguyen, A. Morishita, H. Shiigi, T. Nagaoka, Anal. Chem. 2018, 90, 1090310909. 


\section{Entry for the Table of Contents}
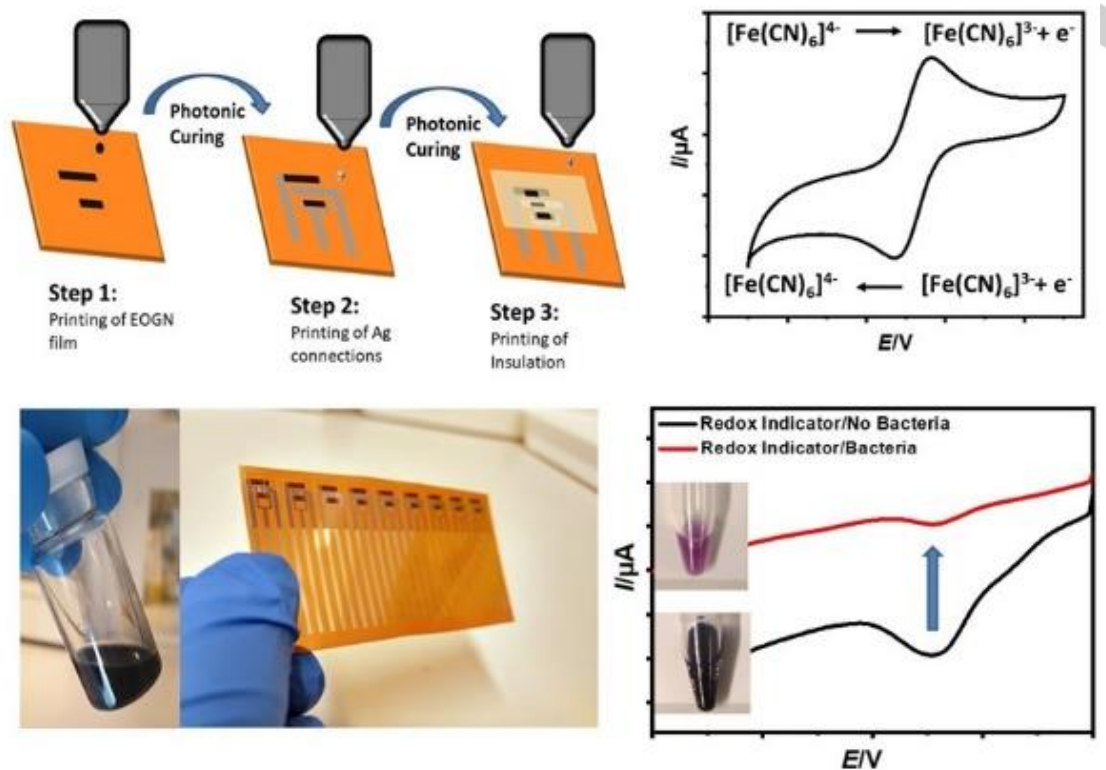

Mildly-edge oxidized graphene nanosheet (EOGN) electrodes on flexible plastic were inkjet printed using a highly loaded EOGN ink. The electrodes gave reproducible electrochemical responses thanks to ink stability and thanks to the fabrication process. The EOGN electrodes, accompanied by printed reference and counter electrodes, were applied as facile electrochemical YES/NO living bacterial cell detector by following the reduction of metabolic redox indicators. 